account of complexities in the sampling theory of all but a few distributions.

As alternatives to normal distribution theory tests are not readily available in practice, it is of interest to know somothing of the effects of using them when they are not theoretically justifiable. I have carried out a series of sampling trials simulating the various situations above for an experiment with three replicates of each of two treatments, there being zero treatment difference. A normal distribution theory $t$-test was used to detect significant differences, and too high a proportion of significant results was nearly always obtained at both the 1 per cent and 5 per cent lovels when normal distribution theory assumptions did not hold. Twelve batteries, each of 200 or more tests, were performed. In only one case, corresponding to random sampling from an exponential distribution, were too few significant results obtained. When testing at the 5 per cent level the proportion of significant rosults was as high as 10 per cent in one battery. With another battery the proportion of results significant at the 1 per cent level was as high as $5 \cdot 7$ per cent. The last two eases involved samples corresponding to situations 1 and 2 , respectively. When normal distribution theory assumptions held, the proportion of significant results was generally close to the test-level, for example, between 5 and 6.7 per cent when testing at the 5 per cent level.

When the alternatives to a small exporiment are no experiment or a long wait, it seems clear that a decision on the course of action should not be divorced from statistical considorations associated with the logical situation. The situations discussed are not exhaustive, but cover a wide range of practical cases.

The points raised apply both to estimation and significance testing, and some of them are worthy of consideration in correlation and regression problems with few pairs of observations.

My thanks are due to Dr. S. C. Pearce for stimulating discussions on the logical status of small experiments.

\section{P. SPRENT}

East Malling Research Station, Maidstono, Kent.

'Pitman, E. J. G., J. Roy. Statist. Soc., Supp., 4, 119 (1937).

\section{Significance of the Difference between Two Means when the Population Variances may be Unequal}

THe purpose of this communication is to present a simple test applicable at the 5 per cent level to the general case of the significance of the difference between two means. If we have two samples of $n_{1}$ and $n_{2}$ variates from normal populations with the same, though unknown, scale factor, that is, $\sigma_{1}=\sigma_{2}$, the significance of the difforence betweon the means can be tested by the eriterion:

$$
t=\left(\bar{x}_{1}-\bar{x}_{2}\right) / \sqrt{ }\left\{\frac{\sum_{1}+\Sigma_{2}}{n_{1}-n_{2}-2}\left(\frac{1}{n_{1}}+\frac{1}{n_{2}}\right)\right\}
$$

whore $\Sigma_{1}$ and $\Sigma_{2}$ represent the sums of squares from the respective means and $t$ is roferred to Student's integral with $n_{1}+n_{2}-2$ degrees of freedom. If the scale factors are unequal the uso of this criterion involves a bias ${ }^{1}$ which is small if $n_{1}=n_{2}$ but which can be large if $n_{1} \neq n_{2}$. When the relative scale factor of the two populations is known, eppropriate woighting of the sums of squares gives an exact solution. In the case where the relative scale factor is unknown, Fisher ${ }^{2,3}$ advocates the use of a different criterion, Bthrens' $d^{4}$, which can be expressed as :

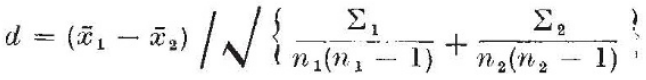

and tables ${ }^{5,6}$ are available for the 5 per cent and 1 per cent points of this distribution for a lattice of values of $n_{1}$ and $n_{2}$ both greater than 6 .

In a previous communication ${ }^{7}$ it was pointed out that when Student's $t$ is standardized by dividing it by its own standard deviation, the variability of the tails with the number of degrees of freedom is greatly reduced and in particular the 5 por cont values of standardized $t$, donoted $t_{8}$, for 4 or moro degrees of freedom all lie within the limits 1.96 and $2 \cdot 0$. With reference to the present problom :

$$
t_{*}=\left(\bar{x}_{1}-\bar{x}_{2}\right) / \sqrt{ }\left\{\frac{\Sigma_{1}+\Sigma_{2}}{n_{1}+n_{2}-4}\left(\frac{1}{n_{1}}+\frac{1}{n_{2}}\right)\right\}
$$

Behrens' $d$ ean be adjusted in a similar way giving :

$$
d_{s}=\left(\bar{x}_{1}-\bar{x}_{2}\right) / \sqrt{ }\left\{\frac{\Sigma_{1}}{n_{1}\left(n_{1}-3\right)}+\frac{\Sigma_{2}}{n_{2}\left(n_{2}-3\right)}\right\}
$$

From the rolationship between Behrens' $d$ and its adjusted value $d_{s}$, implicit in the above formula, the value of $d_{s}$ corresponding to each value of $d$ in the 5 per cont table was calculated with the remarkable result that all these values of $d_{s}$ lie within the range I.96 to 2.0 whereas $d$ itself ranges from 1.960 to 2.447 . Hence, provided that $n_{1}$ and $n_{2}$ are both greater than 6 , if $d_{s} \geqslant 2$ the difference betwoon the means is significant at the 5 per cont level; if $d_{s}<1.96$, the differonce is not significant. The formula was suggested by Welch but he did not give numerical values.

When $n_{1}=n_{2}=n$, say, the formula for $t$ and $d$ are identical but the numerical values for a given level of significance are different ; $d$ is more stringent. The corresponding adjusted criteria are :

$$
t_{s}=\left(\bar{x}_{1}-\bar{x}_{2}\right) / \sqrt{ }\left\{\frac{\Sigma_{1}+\Sigma_{0}}{n(n-z)}\right\}
$$

and

$$
d_{8}=\left(\bar{x}_{1}-\bar{x}_{2}\right) / \sqrt{ }\left\{\frac{\Sigma_{1}+\Sigma_{2}}{n(n-3)}\right\}
$$

Both lie between 1.96 and $2 \cdot 0$ dit the 5 per cent point for $n>6$. The factor $n-3$ compared with $n-2$ roflects the absence of information about the relative scale factors of the two populations.

JOHN B. DE V. WEIR

University of Glasgow, (xlasgow, W.2.

Welch, B. L., Biometrika, 29, 350 (1938).

2 Fisher, R. A., Ann. Eugen., 6, 301 (1935).

"Fisher, R. A., "Statistical Methods and Seientifie Inference", 94 (1956).

' Behrens, W.-U., Landw. Jb., 68, 807 (1929).

SSukhatme, P. V., Sankhya, 4, 39 (1938).

"Hisher, R. A., and Xates, F., "Statistical Tables for Biological, Agricultural and Medical Research", fifth ed. (1957)

7 Weir, J. B. de V., Nature, 185, 558 (1960). 